\title{
The Photosynthetic Characteristics of 'Chaling' Common Wild Rice (Oryza rufipogon Griff.) under Cold Stress
}

\author{
Xiang MO, Mengliang XU* \\ Hunan Normal University, College of Life Science, Changsha 410081, \\ China; moxiang2013cs@163.com; xml2012cs@126.com (*corresponding author)
}

\begin{abstract}
'Chaling' common wild rice (CWR, Oryza rufipogon Griff.), found in Chaling county, Hunan province, China, is one of the only two wild rice populations grown northernmost in the world. Although the cold tolerance of 'Chaling' CWR is extremely strong, its photosynthetic characteristics under cold stress remain unknown. In this study, the photosynthetic parameters of leaves at tiller stage in 'Chaling' CWR were first determined under the conditions of cold stress $\left(15^{\circ} \mathrm{C}\right)$ and normal temperature $\left(28^{\circ} \mathrm{C}\right)$, and then compared with those in the standard rice cultivars including indica 'Guangluai $4^{\prime}$ ', indica 'Y-Liangyou 1' (a Chinese hybrid rice with super high grain yield), and japonica 'Nipponbare' under the same temperature conditions. The results showed that the net photosynthetic rate, the total chlorophyll and total carotenoid contents, the maximum quantum yield of PSII, the apparent quantum yield, and the carboxylation efficiency in 'Chaling' CWR were all significantly higher than those in the standard rice cultivars under cold stress $(\mathrm{P}<0.05)$. The ratios of these parameters in 'Chaling' CWR under cold stress to those under normal temperature condition were $47.9 \sim 84.9 \%$, much higher than those in the standard rice cultivars, which were $3.1 \sim 73.8 \%$. These results indicate that the photosynthetic characteristics of 'Chaling' CWR under cold stress are excellent. Our findings would have an enormous benefit if the trait of the cold stress tolerance of 'Chaling' CWR is transferred to the cultivated rice via the traditional breeding or molecular breeding.
\end{abstract}

Keywords: apparent quantum yield, carboxylation efficiency, chlorophyll fluorescence, photosynthetic pigment, photosynthetic rate

Abbreviations: A- $\mathrm{C}_{\mathrm{i}}$ curve - assimilation rate plotted against intercellular $\mathrm{CO}_{2}$ concentration, $\mathrm{AQY}$ - apparent quantum yield, Car - carotenoids, CE - carboxylation efficiency, Chl - chlorophyll, CWR - common wild rice, $\mathrm{F}_{\mathrm{o}}$ - the minimal chlorophyll fluorescence value, $F_{m}$ - the maximum chlorophyll fluorescence value, $F_{v} / F_{m}$ - variable to maximum fluorescence, $P_{n}$ - net photosynthetic rate.

\section{Introduction}

Common wild rice (CWR, Oryza rufipogon Griff.) is the close relative species of the cultivated rice (Oryza sativa L.), however, its genetic diversity is much richer (Cheng et al., 2012; Liu et al., 2015; Shishido et al., 2006; Sun et al., 2001; Vaughan et al., 2003; Wang et al., 2007). CWR possesses some unique quantitative trait loci (QTLs) which attribute to its special features such as the disease/pest resistance, the abiotic stresses tolerance, etc. (Ma et al., 2015; Vaughan et al., 2003; Xiao et al., 1996; Xiao et al., 1998). Therefore, CWR can be utilized as an important germplasm to improve the cultivated rice in terms of disease/pest resistance, adaptability, grain yield, and grain quality. 'Chaling' CWR, distributed in a wetland named "Huli" $\left(26^{\circ} 50^{\prime} \mathrm{N}\right)$, Yaoshui town, Chaling county, Hunan province, China (Liu et al., 2001; Song et al., 2005), is one of the CWR populations widely distributed in the world. More importantly, it is one of the only two wild rice populations grown northernmost in the word (Liu et al., 2001). The cold tolerance of 'Chaling' CWR is very strong as it can naturally and easily survive in the winter in its habitat, Chaling county (Sun, 1988) and even in the further and colder northern place, i.e., Changsha city $\left(28^{\circ} 13^{\prime} \mathrm{N}\right)$, Hunan province, China (based on our consecutive observations for more than 10 years). Therefore, 'Chaling' CWR provides a valuable genetic resource for studying the cold tolerance of rice and certainly can be utilized to improve the cold tolerance of the cultivated rice by breeding or other genetic approaches. 
Much progress has been made on the studies of 'Chaling' CWR's geographical distribution and habitat, botanical characters and classification, anti-diseases/pests, abiotic stress tolerance, etc. (Li et al., 2001; Song et al., 2005; Sun, 1988; Xu et al., 2009). However, the photosynthetic characteristics of 'Chaling' CWR under cold stress remain unknown. There are a few research reports on the photosynthesis of CWR, but these studies were only focused on their photosynthetic characteristics under the optimum temperature condition (Kang et al., 2007; Kiran et al., 2013; Masumoto et al., 2004; Yeo et al., 1994; Zhao et al., 2008; Zhao et al., 2010). Although the cold stress tolerance property of 'Chaling' CWR is well known, its photosynthetic ability under cold stress is little known.

This study aims at exploring the photosynthetic characteristics of 'Chaling' CWR under cold stress through a comparative analysis of the photosynthetic parameters such as the net photosynthetic rate $\left(\mathrm{P}_{\mathrm{n}}\right)$, the total chlorophyll (Chl) and carotenoids (Car) contents, the variable to maximum fluorescence $\left(\mathrm{F}_{\mathrm{v}} / \mathrm{F}_{\mathrm{m}}\right)$, the apparent quantum yield (AQY), and the carboxylation efficiency (CE) between "Chaling' CWR and the standard rice cultivars. Our data show the superiority of 'Chaling' CWR in terms of photosynthetic characteristics under cold stress as compared to the standard rice cultivars.

\section{Materials and Methods}

\section{Plant material}

The seeds of 'Chaling' CWR (Oryza rufipogon Griff.) were obtained from its tillers grown in an experimental paddy field in Hunan Normal University (Changsha, Hunan province, China). The tillers of 'Chaling' CWR for seed production were collected from its natural habitat, a swamp place named 'Huli' $\left(26^{\circ} 50^{\prime} \mathrm{N}\right)$, Chaling county, Hunan province, China(Sun, 1988; Liu et al., 2001; Song et al., 2005). The seeds of standard rice cultivars (Oryza sativa L.) including indica 'Guangluai 4', indica super high grain yield hybrid 'YLiangyou 1', and japonica 'Nipponbare' were provided by Life Science College, Hunan Normal University.

\section{Cultivation and management of 'Chaling' CWR and the standardrice cultivars}

The seeds of 'Chaling' CWR and the standard rice cultivars were sterilized with $0.1 \% \mathrm{HgCl}_{2}$ for $10 \mathrm{~min}$ and washed 3 times with the distilled water, then soaked for 3 days at $25^{\circ} \mathrm{C}$ (the water was changed once a day), and incubated at $37^{\circ} \mathrm{C}$ for 2 or 3 days for germination. After the germination, these seeds were sown in the pots filled with wet soil ( $3.5 \mathrm{Kg}$, dry weight) in the early season suitable for rice planting in natural condition in Changsha. When the seedlings grew up to 4 leaves, they were transplanted into other pots ( 2 seedlings per pot) to grow again in the natural condition. Six pots of plants for 'Chaling' CWR and every cultivar rice variety were prepared. The contents of total nitrogen, total phosphorus, total potassium, and organic matter in the soil in pots were $0.156 \%, 0.067 \%, 1.12 \%$, and $4.06 \%$, respectively, and the contents of available nitrogen, available phosphorus, and available potassium were $0.013 \%$, $0.003 \%$, and $0.011 \%$, respectively, which were rich for the growth of seedlings of 'Chaling' CWR and the standard rice cultivars. Seven days after the transplanting of the seedlings, each pot was added $1 \mathrm{~g}$ urea and $2 \mathrm{~g}$ compounded fertilizer to keep the available nitrogen, phosphorus, and potassium enough. For water management, each pot kept a water layer of $2-3 \mathrm{~cm}$ above the soil surface until the seedlings grew to tiller stage for cold stress treatment. The conventional diseases and insects control were applied.

\section{cultivars}

Cold treatments of 'Chaling' CWR and the standard rice

Two weeks after the transplanting of the seedlings, the plants of 'Chaling' CWR and the standard rice cultivars at the tiller stage were divided equally into two groups, i.e., three pots (6 plants) per genotype for each group. Two groups of rice plants in pots were put into two PGC15.5 plant growth chambers (Percival Scientific, Inc., Perry, Iowa, USA), respectively. One group of plants grew under cold stress at 15 ${ }^{\circ} \mathrm{C}$ (14 h light, $1000 \mu \mathrm{mol} \cdot \mathrm{m}^{-2} \mathrm{~s}^{-1}$ light intensity $) / 10{ }^{\circ} \mathrm{C}(10 \mathrm{~h}$ dark, $0 \mu \mathrm{mol} \cdot \mathrm{m}^{-2} \mathrm{~s}^{-1}$ light intensity) with a relative humidity of $75 \%$. The other group of plants grew under normal temperature at $28^{\circ} \mathrm{C}(14 \mathrm{~h}$ light $) / 22^{\circ} \mathrm{C}(10 \mathrm{~h} \mathrm{dark})$ with the same light intensity and relative humidity as the cold treatment. Seven days later, the photosynthetic parameters were measured.

\section{$P_{n}$ measurement}

Net photosynthetic rate $\left(\mathrm{P}_{\mathrm{n}}\right)$ on the second upper leaf was measured from 09:00 to 11:00 AM using a LI-6400 portable photosynthesis system (Li-Cor, Inc., Lincoln, Nebraska, USA) with photosynthetic active radiation (PAR) of $1500 \mu \mathrm{mol}^{-2} \mathrm{~s}^{\mathrm{s}}$ ${ }^{1}$ in the leaf chamber controlled by its 6400-02B LED Light Source and $\mathrm{CO}_{2}$ concentration of $400 \mu \mathrm{mol} \cdot \mathrm{mol}^{-1}\left(\mathrm{CO}_{2} /\right.$ air $)$ controlled by its $6400-01 \mathrm{CO}_{2}$ Injector with 12 -gram liquefied $\mathrm{CO}_{2}$ cartridge. The leaf temperature was controlled at $15^{\circ} \mathrm{C}$ for cold stress treatment and $28{ }^{\circ} \mathrm{C}$ for normal temperature condition by the equipment. $\mathrm{P}_{\mathrm{n}}$ of six leaves ( 1 leaf per plant) for each genotype (including 'Chaling' CWR and three rice cultivars) in each group under cold stress or normal temperature condition was measured.

\section{$A Q Y$ and $C E$ measurements}

Apparent quantum yield (AQY) and carboxylation efficiency $(\mathrm{CE})$ of the second upper leaves of rice plants were obtained from the light response curve $\left(\mathrm{P}_{\mathrm{n}}\right.$ plotted against $\mathrm{PAR}$ ) and the A-C $\mathrm{C}_{\mathrm{i}}$ curve (assimilation rate plotted against intercellular $\mathrm{CO}_{2}$ concentration), respectively, measured from 09:00 to 11:00 AM using LI-6400 portable photosynthesis system. The initial slope (PAR $\leq 200 \mu$ mol. $\mathrm{m}^{-2} \mathrm{~s}^{-1}, \mathrm{C}_{\mathrm{i}} \leq 200 \mu$ mol.mol ${ }^{-1}$ ) of the curves was AQY or CE. At least 3 leaves (1 leaf per pot) were measured for each genotype in each group under cold stress $\left(15^{\circ} \mathrm{C}\right)$ or normal temperature condition $(28$ ${ }^{\circ} \mathrm{C}$ ) for the light curve or the A-Cir curve. The automatic programs for both curves were used. For the light curve, the PAR was set at 1500, 1000, 500, 200, 150, 100, 50, $25 \mu$ mol.m ${ }^{2} \mathrm{~s}^{-1}$, and the $\mathrm{CO}_{2}$ concentration was $400 \mu \mathrm{mol}^{-\mathrm{mol}^{-1}}$ in the leaf chamber. For the A-C curve, the $\mathrm{CO}_{2}$ concentration was set at $400,300,200,150,100,50,25 \mu$ mol.mol $^{-1}$, and the PAR was $1500 \mu \mathrm{mol} \cdot \mathrm{m}^{-2} \mathrm{~s}^{-1}$ in the leaf chamber. Before the automatic programs were used, the test leaves were initially adapted under the PAR of $1500 \mu \mathrm{mol} \cdot \mathrm{m}^{-2} \mathrm{~s}^{-1}$ for $15 \mathrm{~min}$ in order to fully adjust stomata. 
406

\section{$F_{v} / F_{m}$ measurement}

The maximum quantum yield of PS II, indexed by variable to maximum fluorescence $\left(\mathrm{F}_{\mathrm{v}} / \mathrm{F}_{\mathrm{m}}\right)$, was determined using a LI6400 portable photosynthesis system with 6400-40 LCF fluorescence and light source accessory following manufacturer's instruction manual. The minimal and maximum chlorophyll fluorescence values $\left(\mathrm{F}_{\mathrm{o}}\right.$ and $\left.\mathrm{F}_{\mathrm{m}}\right)$ were determined after the full dark adaptation $(30 \mathrm{~min})$. The $\mathrm{F}_{\mathrm{v}} / \mathrm{F}_{\mathrm{m}}$ was calculated based on the equation of $F_{v} / F_{m}=\left(F_{m}-F_{o}\right) / F_{m}$. Six leaves in total (1 leaf per plant) for each genotype in each group were taken to determine their $\mathrm{F}_{\mathrm{v}} / \mathrm{F}_{\mathrm{m}}$ values under cold stress $\left(15^{\circ} \mathrm{C}\right)$ or normal temperature condition $\left(28^{\circ} \mathrm{C}\right)$.

\section{Analysis of photosynthetic pigment content}

Total chlorophyll (chlorophyll a + chlorophyll b) and total carotenoid contents of the second upper leaf blade extracts were measured following Lichtenthaler's method (Lichtenthaler and Wellburn, 1983). Six leaves in total (1 leaf per plant) for each genotype in each group were taken to measure their photosynthetic pigment contents under cold stress $\left(15^{\circ} \mathrm{C}\right)$ or normal temperature condition $\left(28^{\circ} \mathrm{C}\right)$.

\section{Statistical analysis}

The values of $\mathrm{P}_{\mathrm{n}}$ in Table $1, \mathrm{~F}_{\mathrm{v}} / \mathrm{F}_{\mathrm{m}}$ in Table 4, total Chl and total Car contents in Fig. 1 and Fig. 2 are means from 6 independent samples, and the values of AQY in Table 2 and $\mathrm{CE}$ in Table 3 are means from at least 3 independent samples. One way ANOVA and Duncan's multiple range tests were used to determine the significant differences among means obtained from 'Chaling' CWR and three standard rice cultivars at the $5 \%$ level. All calculations were performed using the statistical software of IBM SPSS Statistics 19.

\section{Results}

Comparison of $P_{n}$ between 'Chaling' CWR and the standard rice cultivars

The $\mathrm{P}_{\mathrm{n}}$ of 'Chaling' CWR under normal temperature condition was not significantly different from that of all the three cultivars (Table 1 ). However, its $P_{n}$ under the cold stress was significantly higher than that of all the three cultivars $(\mathrm{P}<$ $0.05)$. Additionally, its ratio (\%) of $P_{n}$ value under cold stress $\left(15^{\circ} \mathrm{C}\right)$ to $\mathrm{P}_{\mathrm{n}}$ value under normal temperature $\left(28^{\circ} \mathrm{C}\right)$ was $47.9 \%$, much higher than those of the three cultivars which were $16.2 \sim 36.8 \%$ (Table 1). Based on these data, we conclude that the photosynthetic capacity of 'Chaling' CWR is stronger than that of standard rice cultivars under the same cold stress.

\section{Comparison of $A Q Y$ between 'Chaling' CWR and the standard rice cultivars}

The AQY of 'Chaling' CWR under normal temperature condition was not significantly different from those of all the three cultivars (Table 2). However, its AQY was significantly higher than those of all the three cultivars under cold stress. Besides this, its ratio (\%) of AQY value under the cold stress to AQY value under normal temperature condition was also higher than those of all the three cultivars (Table 2). These results indicate that the light utilization efficiency of 'Chaling' CWR is higher than those of all the three cultivars under cold stress.

\section{Comparison of CE between 'Chaling' CWR and the standard rice cultivars}

The CE value of 'Chaling' CWR was almost equal to those of all the three standard rice cultivars under normal temperature, but significantly higher than those of all the three standard rice cultivars under cold stress (Table 3 ). In addition, its ratio (\%) of CE value under cold stress to $\mathrm{CE}$ value under normal temperature was much higher than those of all the three standard rice cultivars (Table 3 ). These results suggest that the 'Chaling' CWR can remain the higher carboxylase activity than all the three standard rice cultivars under the cold stress.

\section{Comparison of $F_{v} / F_{m}$ between 'Chaling' $C W R$ and the standard rice cultivars}

The value of $F_{v} / F_{m}$ is a parameter to assess the maximum photosynthetic capacity of PS II, especially under stress. Under normal temperature condition, the value of $F_{v} / F_{m}$ of 'Chaling' CWR was not significantly different from those of the three standard rice cultivars (Table 4 ). Under cold stress, however, the value of $\mathrm{F}_{\mathrm{v}} / \mathrm{F}_{\mathrm{m}}$ of 'Chaling' CWR was significantly higher than those of three standard rice cultivars. In addition, the ratio (\%) of $\mathrm{F}_{\mathrm{v}} / \mathrm{F}_{\mathrm{m}}$ value under cold stress to $F_{v} / F_{m}$ value under normal temperature condition in 'Chaling' CWR was also higher than those in three standard rice cultivars (Table 4). This feature of 'Chaling' CWR indicates its photochemical reaction of PS II can be maintained at a high level to reduce adverse effects on photosynthesis under cold stress.

Comparison of photosynthetic pigment content between 'Chaling' CWR and the standard rice cultivars

The photosynthetic pigment content is closely related to the photosynthesis. Under normal temperature condition, the total $\mathrm{Chl}$ content in 'Chaling' CWR was not significantly different from

Table 1. Comparison of net photosynthesis rates $\left(\mathrm{P}_{\mathrm{n}}\right)$ between 'Chaling' CWR and three standard rice cultivars under the normal temperature and cold stress conditions

\begin{tabular}{|c|c|c|c|}
\hline \multirow{2}{*}{ Genotypes } & \multicolumn{2}{|c|}{$\mathrm{P}_{\mathrm{n}}\left(\mu \mathrm{mol} \mathrm{CO} 2 \cdot \mathrm{m}^{-2} \mathrm{~s}^{-1}\right)$} & \multirow{2}{*}{$\begin{array}{c}P_{n} \text { under cold stress } / P_{n} \text { under } \\
\text { normal temperature }(\%)\end{array}$} \\
\hline & Normal temperature & Cold stress & \\
\hline ‘Chaling' CWR & $28.0 \pm 1.5 \mathrm{a}$ & $13.4 \pm 1.8 \mathrm{a}$ & 47.9 \\
\hline 'Nipponbare' & $26.1 \pm 2.5 \mathrm{a}$ & $9.6 \pm 2.2 \mathrm{~b}$ & 36.8 \\
\hline 'Y-Liangyou 1' & $27.2 \pm 1.8 \mathrm{a}$ & $4.6 \pm 1.2 c$ & 16.9 \\
\hline 'Guangluai 4' & $26.5 \pm 2.1 \mathrm{a}$ & $4.3 \pm 1.1 \mathrm{c}$ & 16.2 \\
\hline
\end{tabular}

Note: the data in the table are means \pm SD. Different letters among genotypes within the same column denote statistical significant differences (Duncan test, $\mathrm{P}<0.05)$. 
Table 2. Comparison of apparent quantum yield (AQY) between 'Chaling' CWR and three standard rice cultivars under the normal temperature and cold stress conditions

\begin{tabular}{|c|c|c|c|}
\hline \multirow{2}{*}{ Genotypes } & \multicolumn{2}{|c|}{$\mathrm{AQY}\left(\mu \mathrm{mol} . \mu \mathrm{mol}^{-1}\right)$} & \multirow{2}{*}{$\begin{array}{l}\text { AQY under cold stress / AQY under } \\
\text { normal temperature }(\%)\end{array}$} \\
\hline & Normal temperature & Cold stress & \\
\hline 'Chaling' CWR & $0.040 \pm 0.003 \mathrm{a}$ & $0.032 \pm 0.003 \mathrm{a}$ & 80.0 \\
\hline 'Nipponbare' & $0.034 \pm 0.007 a$ & $0.022 \pm 0.004 \mathrm{~b}$ & 64.7 \\
\hline 'Y-Liangyou 1' & $0.035 \pm 0.005 a$ & $0.017 \pm 0.002 \mathrm{bc}$ & 48.6 \\
\hline 'Guangluai 4’ & $0.034 \pm 0.006 \mathrm{a}$ & $0.015 \pm 0.002 c$ & 44.1 \\
\hline
\end{tabular}

that of japonica cultivar 'Nipponbare' except slightly higher than those of indica cultivars 'Y-Liangyou 1' and 'Guangluai 4', and there was no significant difference in the total Car content between 'Chaling' CWR and the three standard rice cultivars (Fig. 1, Fig. 2). Under cold stress, however, both total Chl content and total Car content of 'Chaling' CWR were significantly higher than those of three standard rice cultivars (Fig. 1, Fig. 2). Moreover, the ratio (\%) of photosynthetic pigment content in 'Chaling' CWR under cold stress to that under normal temperature condition was much higher than those in the three standard rice cultivars. This special photosynthetic trait of 'Chaling' CWR would enhance its light reaction and protect its photosynthetic structure from damage under cold stress.

\section{Discussion}

The photosynthetic capacity of 'Chaling' CWR under cold stress and its potential value in genetic improvement of rice cultivars

Cold stress can be classified as both chilling stress (0$\left.15^{\circ} \mathrm{C}\right)$ and freezing stress $\left(<0{ }^{\circ} \mathrm{C}\right)(\mathrm{Zhu}$ et al., 2007). It is one of major abiotic stresses that influences the photosynthesis and the other metabolic and physiological processes of crops, hence limits their growth, productivity, and geographical distribution (Ashraf and Harris, 2013; Zhang et al., 2014). Rice, originated in tropical or subtropical region, is a thermophilic food crop. Most of its varieties, especially those of widely grown indica varieties and indica hybrids, are sensitive to cold stress. Cold stress can seriously influence rice grain quality or reduce yield in high-latitude or high-altitude regions of China, Japan, Korea, and other parts of the world (Jena et al., 2012). So enhancing the cold tolerance of rice cultivars is desired in order to alleviate the impact of cold stress on them. The photosynthetic capacity of rice under cold stress is an important aspect of its cold tolerance, and some photosynthetic parameters like Pn, Chl content, and $F_{v} / F_{m}$ can be used as indicators of cold tolerance (Wang and Guo, 2007; Xu et al., 2009; Zhang et al., 2014). Therefore, improving the photosynthetic capacity of rice under cold stress is vital for its cold tolerance.

Many studies have shown that the photosynthesis of cultivated rice was adversely affected by cold stress, but the influenced degree differs with genotypes. Lin and Ehleringer (1989) found that both net photosynthesis and quantum yield of rice seedling were declined along the similar trend when the leaf temperature was below $20{ }^{\circ} \mathrm{C}$, and chilling treatment $\left(6-12^{\circ} \mathrm{C}\right)$ at high light $\left(1200 \mu \mathrm{mol}^{\mathrm{mol}}{ }^{-1}\right)$ for 2 hours markedly inhibited quantum yield for 34-74\% and net photosynthesis for

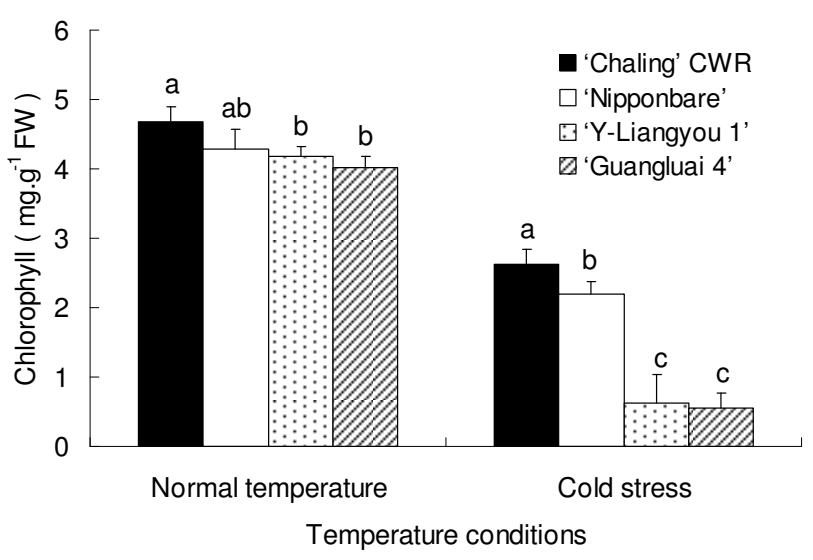

Fig. 1. Comparison of total chlorophyll content between 'Chaling' CWR and three standard rice cultivars under the normal temperature and cold stress conditions. The data in the figure are means \pm SD. Different letters among genotypes at the same temperature denote statistical significant differences (Duncan test, $\mathrm{P}<0.05$ ).

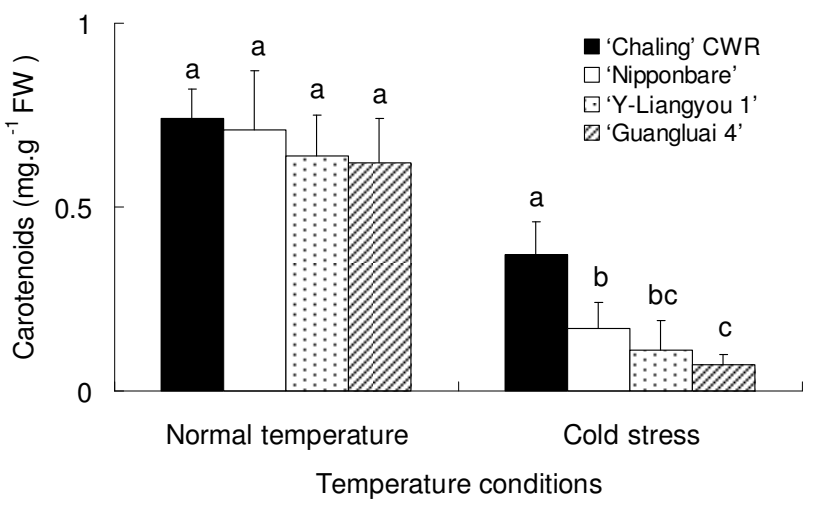

Fig. 2. Comparison of total carotenoids content between 'Chaling' CWR and three standard rice cultivars under the normal temperature and cold stress conditions. The data in the figure are means \pm SD. Different letters among genotypes at the same temperature denote statistical significant differences (Duncan test, $\mathrm{P}<0.05$ ). 
Table 3. Comparison of carboxylation efficiency (CE) between 'Chaling' CWR and three standard rice cultivars under the normal temperature and cold stress conditions

\begin{tabular}{cccc}
\hline Genotypes & \multicolumn{2}{c}{ CE $\left(\mathrm{mol} \cdot \mathrm{m}^{-2} \mathrm{~s}^{-1}\right)$} & \multicolumn{2}{c}{$\begin{array}{c}\text { CE under cold stress / CE under } \\
\text { normal temperature }(\%)\end{array}$} \\
\cline { 2 - 3 } & Normal temperature & $0.062 \pm 0.008 \mathrm{a}$ & \\
\hline 'Chaling' CWR & $0.113 \pm 0.025 \mathrm{a}$ & $0.047 \pm 0.008 \mathrm{~b}$ & \\
'Nipponbare' & $0.103 \pm 0.012 \mathrm{a}$ & $0.032 \pm 0.005 \mathrm{c}$ & \\
'Y-Liangyou 1' & $0.105 \pm 0.007 \mathrm{a}$ & $0.022 \pm 0.006 \mathrm{~d}$ & 35.6 \\
'Guangluai 4' & $0.098 \pm 0.013 \mathrm{a}$ & 22.4 & \\
\hline
\end{tabular}

Note: the data in the table are means \pm SD. Different letters among genotypes within the same column denote statistical significant differences $($ Duncan test, $\mathrm{P}<0.05)$.

Table 4. Comparison of maximum quantum yield of PS II $\left(\mathrm{F}_{\mathrm{v}} / \mathrm{F}_{\mathrm{m}}\right)$ between 'Chaling' CWR and three standard rice cultivars under the normal temperature and cold stress conditions

\begin{tabular}{ccccc}
\hline Genotypes & & $\mathrm{F}_{\mathrm{v}} / \mathrm{F}_{\mathrm{m}}$ & \multicolumn{2}{c}{$\begin{array}{c}\mathrm{F}_{\mathrm{v}} / \mathrm{F}_{\mathrm{m}} \text { under cold stress } / \mathrm{F}_{\mathrm{v}} / \mathrm{F}_{\mathrm{m}} \text { under } \\
\text { normal temperature }(\%)\end{array}$} \\
\cline { 2 - 4 } & Normal temperature & Cold stress & $0.706 \pm 0.014 \mathrm{a}$ & \\
\hline 'Chaling' CWR & $0.831 \pm 0.008 \mathrm{a}$ & $0.629 \pm 0.049 \mathrm{~b}$ & \\
'Nipponbare' & $0.842 \pm 0.004 \mathrm{a}$ & $0.565 \pm 0.044 \mathrm{~b}$ & \\
'Y-Liangyou 1' & $0.835 \pm 0.005 \mathrm{a}$ & $0.433 \pm 0.042 \mathrm{c}$ & \\
'Guangluai 4' & $0.840 \pm 0.006 \mathrm{a}$ & 67.7 & \\
\hline
\end{tabular}

Note: the data in the table are means \pm SD. Different letters among genotypes within the same column denote statistical significant differences (Duncan test, $\mathrm{P}<0.05)$.

46-89\%. It was reported that cold stress $\left(13{ }^{\circ} \mathrm{C}, 24\right.$ hours) affected the photosynthesis of rice seedling drastically, both at the molecular and the physiological level (do Amaral et al., 2016). He et al. (1987) reported that the net photosynthetic rate and chlorophyll content of flag leaf in indica cultivar hybrid rice 'Shanyou 6 ' reduced by $50 \%$ and $24 \%$, respectively, after the low temperature treatment $\left(16^{\circ} \mathrm{C}\right.$, 3 days) at heading stage. Pramod and Vinay (2007) observed a significant reduction in rates of photosynthesis and level of total chlorophyll at grain filling stage under the natural low temperature condition (mean temperature $<18^{\circ} \mathrm{C}$ and minimum temperature $<12^{\circ} \mathrm{C}$ ) by a field experiment with 15 rice (Oryza sativa L.) genotypes. Wang et al. (2006) reported that the photosynthetic rates and chlorophyll content of flag leaves of two rice hybrids decreased considerably after 4 days of low temperature $\left(25 / 15{ }^{\circ} \mathrm{C}\right.$, day and night temperature) treatment at milky stage. Li et al. (1994) found that the $P_{n}$ and AQY of cultivar rice hybrids 'Xiushui 57' and 'Shanyou 63' decreased significantly after artificial cold stress (1 ${ }^{\circ} \mathrm{C}$ for 2 days) or natural cold stress (minimum temperature less than $12{ }^{\circ} \mathrm{C}$ ) at milky stage, but the decreased degree in cold tolerance japonica hybrid rice 'Xiushui 57 ' is much lower than that in cold sensitive indica hybrid 'Shanyou 63'. Wang and Guo (2007) reported that the chlorophyll content, the photosynthetic rate, and the $\mathrm{F}_{\mathrm{v}} / \mathrm{F}_{\mathrm{m}}$ were decreased in the two tested rice cultivars under chilling stress $\left(8^{\circ} \mathrm{C}, 3\right.$ days $)$, and these parameters were decreased even more in the chilling sensitive cultivar than in the chilling tolerant cultivar. Our data support the findings of above studies, i.e., the photosynthesis of all the tested rice genotypes is influenced by cold stress, but the influenced degree in the cold tolerant genotype is smaller than that in the cold sensitive genotype. More importantly, our data show for the first time that the photosynthetic capacity of 'Chaling' CWR under cold stress is not only stronger than that of the cold sensitive indica 'Guangluai 4' and 'Y-Liangyou 1', but also stronger than that of the cold tolerant japonica 'Nipponbare'. This advantageous photosynthetic trait of 'Chaling' CWR should be able to be transferred into cultivar rice varieties through breeding or other genetic approaches so as to improve their photosynthetic capacity under cold stress. This is helpful to expand the temporal and spatial distribution of cultivar rice varieties by making the full use of the temperature and light resources, and greatly improve the grain yield and grain quality.

\section{The study addsphotosynthetic knowledge in wild rice}

The photosynthesis of CWR has been reported before, but those works only have shown the photosynthetic characteristics of CWR under normal temperature condition (Masumoto et al., 2004; Yeo et al., 1994; Zhao et al., 2008; Zhao et al, 2010). The study about photosynthetic characteristics of CWR under cold stress, however, has not been reported. Our study is the first report on the photosynthetic characteristics of 'Chaling' CWR under cold stress. The results clearly show its photosynthetic capacity under cold stress is much stronger than those of the standard rice cultivars. The reasons for this could be that 'Chaling' CWR can maintain higher total Chl and total Car contents, $\mathrm{F}_{\mathrm{v}} / \mathrm{F}_{\mathrm{m}}, \mathrm{AQY}$, and $\mathrm{CE}$ than the standard rice cultivars under cold stress. These data provide the solid foundation for us to further understand the photosynthesis in wild rice. In the future, it is necessary to further study at both physiological and molecular level why the photosynthetic capacity of 'Chaling' CWR is superior under cold stress.

\section{Conclusions}

The values of $P_{n}$, total Chl and total Car contents, $F_{v} / F_{m}$, AQY, and CE in 'Chaling' CWR were significantly higher than those in the typical rice cultivars under cold stress, and the ratios of these values in 'Chaling' CWR under cold stress to those values under normal temperature condition were much higher than those in the typical rice cultivars. Based on these results, it is concluded that the photosynthetic characteristics of 'Chaling' CWR under cold stress are excellent. These excellent photosynthetic traits can be utilized to improve the photosynthetic capacity of rice cultivars under cold stress in order to expand their temporal and spatial distribution, thereby to increase their grain yield. 


\section{Acknowledgements}

This work was supported by Hunan Provincial Natural Science Foundation of China (10JJ3028), Key Scientific Research Project of Education Department of Hunan Province, China (10A072), Key Project Funding of Science and Technology Program of Hunan Province, China (2012FJ2013), Hunan Provincial Construct Program of the Key Discipline in Ecology (0713), the Cooperative Innovation Center of Engineering and New Products for Developmental Biology of Hunan Province (20134486), Scientific Research Funding of Key Laboratory of Agroecological Processes in Subtropical Region, Institute of Subtropical Agriculture, Chinese Academy of Sciences (ISA2015201 ), and Hunan Provincial Key Laboratory of Crop Sterility Mechanism and Sterile Germplasm Resources Innovation (2016TP1011). The authors thank Dr. Hua He (TissueTech, Miami, FL, USA) for his critical reading and revision.

\section{References}

Ashraf M, Harris PGC (2013). Photosynthesis under stressful environments: an overview. Photosynthetica 51 (2):163-190.

Cheng ZQ, Ying FY, Li DQ, Yu TQ, Fu J, Yan HJ, ... Huang XQ (2012). Genetic diversity of wild rice species in Yunnan province of China. Rice Science 19(1):21-28.

do Amaral MN, Arge LWP, Benitez LC, Danielowski R, Silveira SFD, Farias DD, ... da Maia LC (2016). Differential expression of photosynthesis-related genes and quantification of gas exchange in rice plants under abiotic stress. Acta Physiologiae Plantarum 38(6) doi: 10.1007/s11738-016-2176-9.

He J, Liu HX, Wang YR, Guo JY (1987). Effects of low temperature on photosynthesis in flag leaves of rice (Oryza sativa L.). Acta Botanica Sinica 29(6):620-628.

Jena KK, Kim SM, Suh JP, Yang CI, Kim YJ (2012). Identification of cold-tolerant breeding lines by quantitative trait loci associated with cold tolerance in rice. Crop Science 51(2):517-523.

Kang GP, Xu GY, Chen Z, Xu ML, Chen LB (2007). Photosynthetic characteristics of Chaling wild rice. Acta Agronomica Sinica 33(9):1558-1562.

Kiran TV, Rao YV, Subrahmanyam D, Rani NS, Bhadana VP, Rao PA, Voleti SR (2013). Variation in leaf photosynthetic characteristics in wild rice species. Photosynthetica 51(3):350358.

Li P, Wang YR, Chen YZ, Liu HX (1994). Effects of chilling temperature on photosynthesis and photosynthate transport in flag leaves of hybrid rice at milky stage. Acta Botanica Sinica 36(1):45-52.

Li YR, Hou XH, Wei ZS, Sun GZ (2001). Assessment of Hunan wild rice resource on disease resistance and innovation of germplasm. Hunan Agricultural Sciences (6):14,18.

Lichtenthaler HK, Wellburn AR (1983). Determinations of total carotenoids and chlorophylls a and b of leaf extracts in different solvents. Biochemical Society Transactions 11(5):591-592.
Lin ZF, Ehleringer J (1989). The response of photosynthesis and quantum yield to low temperature and high light in leaves of rice seedlings. Acta Botanica Sinica 31(3):198-204.

Liu GH, Wang HY, Zhou J, Guo YH (2001). Spatial distribution and niche analysis of dominant species at the Oryza rufipogon reserve in Chaling, Hunan. Acta Phytoecologica Sinica 25(1):6570.

Liu W, Shahid MQ, Bai L, Lu ZZ, Chen YH, Jiang L, ... Lu YG (2015). Evaluation of genetic diversity and development of a core collection of wild rice (Oryza rufipogon Griff.) populations in China. PLoS One 10(12), e0145990.

Ma Y, Dai XY, Xu YY, Luo W,Zheng XM,Zeng D, ... Chong K (2015). COLD1 confers chilling tolerance in rice. Cell 160:1-13.

Masumoto C, Ishii T, Kataoka S, Hatanaka T, Uchida N (2004). Enhancement of rice leaf photosynthesis by crossing between rice, Oryza sativa, and wild rice species, Oryza rufipogon. Plant Production Science 7(3):252-259.

Pramod K, Vinay M (2007). Effect of low temperature stress on photosynthesis, total soluble sugars, grain filling rate and yield in rice (Oryza sativa L.). Indian Journal of Plant Physiology 12(3):253-260.

Shishido R, Kikuchi M, Nomura K, Ikehashi H ( 2006 ). Evaluation of genetic diversity of wild rice (Oryza rufipogon Griff.) in Myanmar using simple sequence repeats (SSRs). Genetic Resources and Crop Evolution 53(1):179-186.

Song ZP, Li B, Chen JK, Lu BR (2005). Genetic diversity and conservation of common wild rice (Oryza rufipogon) in China. Plant Species Biology 20(2):83-92.

Sun CQ, Wang XK, Li ZC, Iwata A, Yoshimura N (2001). Comparison of the genetic diversity of common wild rice (Oryza rufipogon Griff.) and cultivated rice (O. sativa L.) using RFLP markers. Theoretical \& Applied Genetics 102(1):157-162.

Sun GZ (1988). Studies on the habitat and characters of Hunan provincial wild rice. Crop Research 29(2):14-16.

Vaughan DA, Morishimay H, Kadowaki K (2003). Diversity in the Oryza genus. Current Opinion in Plant Biology 6(2):139-146.

Wang GL, Guo ZF (2007). Effects of phosphorus nutrient on photosynthetic characteristics in rice cultivars with different coldsensitivity. Acta Agronomica Sinica 33(8):1385-1389.

Wang J, Zhang CJ, Chen GX, Wang P, Shi DW, Lu CG (2006). Responses of photosynthetic functions to low temperature in flag leaves of rice genotypes at the milky stage. Rice Science 13(2):113119.

Wang YP, Wei XH, Yuan XP, Yu HY, Xu Q, Tang SX (2007). Analysis on genetic diversity of natural populations of Oryza rufipogon distributed in Hainan province by SSR markers. Chinese Journal of Rice Science 21(6):573-578.

Xiao JH, Grandillo S, Ahn SN, McCouch SR, Tanksley SD, Li JM, Yuan LP (1996). Genes from wild rice improved yield. Nature 384:223-224.

Xiao JH, Li JM, Grandillo S, Ahn S N, Yuan LP, Tanksley SD, McCouch SR (1998). Identification of trait-improving quantitative trait loci alleles from a wild rice relative Oryza rufipogon. Genetics 150(2):899-909. 
410

Xu ML, Chen Z, Xiao Y, Cui YC, Xu GY, Xia XJ (2009). Studies on cold tolerance of Chaling CWR at seedling stage. Acta Laser Biology Sinica 18(6):805-809.

Yeo ME, Yeo AR, Flowers TJ (1994). Photosynthesis and photorespiration in the genus Oryza. Journal of Experimental Botany 45(5):553-560.

Zhang Q, Chen QH, Wang SL, Hong YH, Wang ZL (2014). Rice and cold stress: methods for its evaluation and summary of cold tolerance-related quantitative trait loci. Rice 7:24 doi: 10.1186/s12284-014-0024-3.
Zhao M, Ding Z, Lafitte R, Sacks E, Dimayuga G, Holt D (2010). Photosynthetic characteristics in Oryza species. Photosynthetica 48(2):234-240.

Zhao M, Lafitte HR, Sacks E, Dimayuga G, Botwright Acuna TL (2008). Perennial O. sativa $\times$ O. rufipogon interspecific hybrids: I. Photosynthetic characteristics and their inheritance. Field Crops Research 106(3):203213. 